\title{
Policy recommendations in response to the resurgence of COVID-19 cases for institutional medical practice from an ophthalmic perspective
}

Chris H.L. Lim ${ }^{1,2,3,4}$, Blanche X.H. Lim ${ }^{1,4}$, Aaron Q.Y. Goh ${ }^{5}$, Dawn K.A. Lim $^{1,4}$, Clement W.T. Tan ${ }^{1,4}$

'Department of Ophthalmology, National University Health System, Singapore; ${ }^{2}$ School of Optometry and Vision Science, University of New South Wales, Sydney, Australia; ${ }^{3}$ Singapore Eye Research Institute, Singapore; ${ }^{4}$ Yong Loo Lin School of Medicine, National University of Singapore, Singapore; '5ee Kong Chian School of Medicine, Nanyang Technological University, Singapore

\begin{abstract}
Objectives: The COVID-19 pandemic has been declared a public health emergency of international concern. Singapore was one of the first countries to identify imported cases and also experience a second wave of outbreaks. A slew of measures enacted by the government to 'flatten the curve' has directly impacted upon the way we practice. Study design/Methods: This article describes steps enacted by our department to ensure sustainability of our ophthalmic practice.

Results: We share considerations at various time points and policies implemented in a stepwise approach in response to the worsening community situation. We further discuss our phased approach towards reinstating our services safely and effectively for patients and staff in a markedly different practice climate.

Conclusions: The COVID-19 pandemic has markedly upended the way we practice medicine. Reflecting on the ideal measures required for such occurrences in the future will empower practices with the ability to respond effectively to future outbreaks.
\end{abstract}

Keywords: COVID-19 response, ophthalmology, public healthcare system, Singapore

\section{Introduction}

The Singaporean experience with the COVID-19 pandemic has been unique. What was initially celebrated as a model response to the pandemic ${ }^{1}$ evolved into an entirely different situation, as the city-state reeled in horror when a second wave of outbreaks hit. ${ }^{2}$ This unexpected second wave of cases was driven by long-standing

Correspondence: Clement Tan, MBBS, MMed (Ophth), FRCSEd, FAMS, Department of Ophthalmology, National University Health System, 1E Kent Ridge Rd, Singapore 119228.

E-mail: clement_wt_tan@nuhs.edu.sg 
Table 1. Operational considerations of our ophthalmic practice in handing the COVID-19 pandemic

\begin{tabular}{|c|c|c|c|c|c|c|}
\hline Stages & $\begin{array}{l}\text { Measures enacted with early signs of an } \\
\text { outbreak }\end{array}$ & $\begin{array}{l}\text { Measures during the } \\
\text { pandemic }\end{array}$ & $\begin{array}{l}\text { Escalated measures to } \\
\text { flatten the curve } \\
\text { (e.g. Circuit Breaker) }\end{array}$ & $\begin{array}{l}\text { Refinement of policies } \\
\text { for sustainability }\end{array}$ & Easing of measures & $\begin{array}{l}\text { Ideal measures to have in } \\
\text { place before outbreak }\end{array}$ \\
\hline \multirow[t]{6}{*}{ Manpower } & $\begin{array}{l}\text { Team segregation plans formed and } \\
\text { refined }\end{array}$ & $\begin{array}{l}\text { Deployment of } \\
\text { segregation plans }\end{array}$ & $\begin{array}{l}\text { Further limiting } \\
\text { manpower deployment } \\
\text { within teams to } \\
\text { minimize exposure }\end{array}$ & $\begin{array}{l}\text { Increase manpower } \\
\text { based on operational } \\
\text { needs }\end{array}$ & Business as usual & $\begin{array}{l}\text { Drawer plans for pandemic } \\
\text { manpower deployment } \\
\text { Sufficient redundancy in } \\
\text { manpower to support } \\
\text { ability to ramp up and } \\
\text { down easily }\end{array}$ \\
\hline & $\begin{array}{l}\text { Establishing cross-institutional cover plans } \\
\text { with other ophthalmic centers }\end{array}$ & $\begin{array}{l}\text { Deployment of plans as } \\
\text { required }\end{array}$ & & & $\begin{array}{l}\text { Maintaining } \\
\text { collaborative networks } \\
\text { and ties }\end{array}$ & $\begin{array}{l}\text { Drawer plans for cross- } \\
\text { cover of patients between } \\
\text { sites }\end{array}$ \\
\hline & $\begin{array}{l}\text { Institutional segregation with restrictions } \\
\text { on cross-institution movement of medical } \\
\text { professionals }\end{array}$ & $\begin{array}{l}\text { Evaluation of essential } \\
\text { services within } \\
\text { department and } \\
\text { establishing need for } \\
\text { certain skill sets }\end{array}$ & & $\begin{array}{l}\text { Permitting cross- } \\
\text { institutional movement } \\
\text { of essential health } \\
\text { professionals }\end{array}$ & Business as usual & $\begin{array}{l}\text { Revisit remuneration and } \\
\text { incentivization of visiting } \\
\text { specialists; even as a } \\
\text { pandemic-related incentive }\end{array}$ \\
\hline & $\begin{array}{l}\text { Identification of vulnerable staff (elderly, } \\
\text { multiple comorbidities, pregnant) }\end{array}$ & $\begin{array}{l}\text { Redeployment of staff } \\
\text { away from patient } \\
\text { contact duties (virtual } \\
\text { clinics, working from } \\
\text { home, administrative } \\
\text { roles) }\end{array}$ & & $\begin{array}{l}\text { Ramping up of scope of } \\
\text { virtual clinics }\end{array}$ & Business as usual & $\begin{array}{l}\text { Maintain registry of staff } \\
\text { meeting criteria }\end{array}$ \\
\hline & $\begin{array}{l}\text { Consideration of social circumstances } \\
\text { such as: } \\
\text { 1. Households with more than one } \\
\text { healthcare/essential worker with care of } \\
\text { child } \\
\text { 2. Placement issues with vulnerable } \\
\text { individuals at home } \\
\text { 3. Overseas-based staff }\end{array}$ & $\begin{array}{l}\text { Provision of temporary } \\
\text { accommodation } \\
\text { Approval of no pay } \\
\text { leave for staff }\end{array}$ & & $\begin{array}{l}\text { Assistance with short- } \\
\text { term accommodation } \\
\text { and living arrangements } \\
\text { in view of extended } \\
\text { cordon sanitaire }\end{array}$ & Business as usual & $\begin{array}{l}\text { Maintain registry of staff } \\
\text { commuting from overseas }\end{array}$ \\
\hline & $\begin{array}{l}\text { Identifying of volunteers to support } \\
\text { critical services (Emergency Departments, } \\
\text { Intensive Care Units, Pandemic Wards) }\end{array}$ & & $\begin{array}{l}\text { Deployment to support } \\
\text { critical services and } \\
\text { community-based } \\
\text { initiatives (e.g. } \\
\text { dormitory-based } \\
\text { swabbing and } \\
\text { community care } \\
\text { facilities) }\end{array}$ & & $\begin{array}{l}\text { Recall staff to assist with } \\
\text { ramping up of } \\
\text { operations }\end{array}$ & $\begin{array}{l}\text { Restructuring clinics to be } \\
\text { consultant-run }\end{array}$ \\
\hline
\end{tabular}




\begin{tabular}{|c|c|c|c|c|c|c|}
\hline Stages & $\begin{array}{l}\text { Measures enacted with early signs of an } \\
\text { outbreak }\end{array}$ & $\begin{array}{l}\text { Measures during the } \\
\text { pandemic }\end{array}$ & $\begin{array}{l}\text { Escalated measures to } \\
\text { flatten the curve } \\
\text { (e.g. Circuit Breaker) }\end{array}$ & $\begin{array}{l}\text { Refinement of policies } \\
\text { for sustainability }\end{array}$ & Easing of measures & $\begin{array}{l}\text { Ideal measures to have in } \\
\text { place before outbreak }\end{array}$ \\
\hline \multirow[t]{5}{*}{ Operations } & $\begin{array}{l}\text { Establish disease outbreak taskforce } \\
\text { within the operations team }\end{array}$ & $\begin{array}{l}\text { Inclusion of further key } \\
\text { personnel within } \\
\text { taskforce as necessary }\end{array}$ & & & $\begin{array}{l}\text { De-escalation of } \\
\text { taskforce }\end{array}$ & $\begin{array}{l}\text { Identification of essential } \\
\text { personnel required for the } \\
\text { disease outbreak taskforce }\end{array}$ \\
\hline & $\begin{array}{l}\text { Determine "high-risk" patients and } \\
\text { escalation protocol }\end{array}$ & $\begin{array}{l}\text { Multi-disciplinary } \\
\text { handshake in } \\
\text { assessment and } \\
\text { diagnostics with care (ie. } \\
\text { transfer of patients from } \\
\text { Ophthalmology to A\&E/ } \\
\text { ID) }\end{array}$ & & & & $\begin{array}{l}\text { Drawer plans for safe } \\
\text { transfer of patients with } \\
\text { airborne transmitted } \\
\text { communicable diseases }\end{array}$ \\
\hline & Reduction of surgical load & $\begin{array}{l}\text { Deferment of non- } \\
\text { essential elective } \\
\text { operations }\end{array}$ & $\begin{array}{l}\text { Further reduction of } \\
\text { Operating lists by } 80 \% \text {. } \\
\text { Only proceed with } \\
\text { sight-threatening } \\
\text { complications }\end{array}$ & $\begin{array}{l}\text { Gradual increase in } \\
\text { operating load }\end{array}$ & Business as usual & $\begin{array}{l}\text { Move to automate and } \\
\text { integrate computer-based } \\
\text { systems to reduce man- } \\
\text { hours needed for shifting }\end{array}$ \\
\hline & Reduction of clinic numbers & $\begin{array}{l}\text { Reduction in clinic } \\
\text { numbers to comply with } \\
\text { team segregation and } \\
\text { social distancing } \\
\text { requirements }\end{array}$ & $\begin{array}{l}\text { Deferment of non- } \\
\text { essential clinical } \\
\text { consultations }\end{array}$ & $\begin{array}{l}\text { Gradual increase in } \\
\text { clinic consultations in } \\
\text { tandem with } \\
\text { community measures } \\
\text { Prioritization of new } \\
\text { consultations and } \\
\text { patients from our } \\
\text { glaucoma and retina } \\
\text { service as clinic } \\
\text { numbers }\end{array}$ & Business as usual & $\begin{array}{l}\text { Move to automate and } \\
\text { integrate computer-based } \\
\text { systems to reduce man- } \\
\text { hours needed for shifting } \\
\text { Decanting patients to } \\
\text { satellite sites and } \\
\text { enrolment in virtual clinics }\end{array}$ \\
\hline & $\begin{array}{l}\text { Identification of clinical conditions and } \\
\text { pathways suitable for virtual clinic }\end{array}$ & $\begin{array}{l}\text { Deployment of virtual } \\
\text { clinic pathways }\end{array}$ & & $\begin{array}{l}\text { Increasing virtual clinic } \\
\text { capacity }\end{array}$ & $\begin{array}{l}\text { Further development of } \\
\text { virtual clinic and tele- } \\
\text { ophthalmology } \\
\text { capabilities }\end{array}$ & $\begin{array}{l}\text { Established virtual clinic } \\
\text { and teleophthalmology } \\
\text { capabilities and pathways }\end{array}$ \\
\hline
\end{tabular}




\begin{tabular}{|c|c|c|c|c|c|c|}
\hline Stages & $\begin{array}{l}\text { Measures enacted with early signs of } \\
\text { an outbreak }\end{array}$ & $\begin{array}{l}\text { Measures during the } \\
\text { pandemic }\end{array}$ & $\begin{array}{l}\text { Escalated measures to } \\
\text { flatten the curve } \\
\text { (e.g. Circuit Breaker) }\end{array}$ & $\begin{array}{l}\text { Refinement of policies } \\
\text { for sustainability }\end{array}$ & Easing of measures & $\begin{array}{l}\text { Ideal measures to have } \\
\text { in place before } \\
\text { outbreak }\end{array}$ \\
\hline \multirow[t]{4}{*}{$\begin{array}{l}\text { Protection } \\
\text { Physical defense }\end{array}$} & $\begin{array}{l}\text { Ascertain mode of transmission and } \\
\text { determine level of protection required } \\
\text { with targeted PPE acquisition }\end{array}$ & $\begin{array}{l}\text { Sourcing and } \\
\text { stockpiling of PPE }\end{array}$ & $\begin{array}{l}\text { Establishing multiple } \\
\text { supply chains for } \\
\text { essentials to ensure } \\
\text { continuity of supplies }\end{array}$ & $\begin{array}{l}\text { Further diversification of } \\
\text { supply chains including } \\
\text { establishing local } \\
\text { manufacturing sites to } \\
\text { mitigate risks of export } \\
\text { embargos }\end{array}$ & $\begin{array}{l}\text { Replenishment of } \\
\text { stockpiles }\end{array}$ & $\begin{array}{l}\text { Ensure adequate } \\
\text { stockpile of PPE }\end{array}$ \\
\hline & $\begin{array}{l}\text { Review of clinical practices to mitigate } \\
\text { risks (e.g. wiping down high-touch } \\
\text { surfaces, cessation of use of air-puff } \\
\text { tonometry and minimization of } \\
\text { aerosolizing procedures) }\end{array}$ & $\begin{array}{l}\text { Constant comparison of } \\
\text { practices against } \\
\text { institutions locally and } \\
\text { worldwide and } \\
\text { published evidence } \\
\text { Evaluation of high-risk } \\
\text { procedures in face of } \\
\text { urgency of treatment }\end{array}$ & & & $\begin{array}{l}\text { Easing of changes in } \\
\text { practice according to } \\
\text { risk profile and impact } \\
\text { on services }\end{array}$ & $\begin{array}{l}\text { Stringent cleaning of } \\
\text { surfaces, especially } \\
\text { high-touch areas } \\
\text { Maintain list of aerosol- } \\
\text { generating procedures } \\
\text { and investigations }\end{array}$ \\
\hline & $\begin{array}{l}\text { Review of reported clinical features and } \\
\text { risk factors for contracting disease (eg. } \\
\text { travel or contact history) }\end{array}$ & $\begin{array}{l}\text { Secure facility by } \\
\text { enforcing universal } \\
\text { mask wearing, thermal } \\
\text { screening and visitor } \\
\text { registration stations } \\
\text { Establish triage process } \\
\text { and protocols to } \\
\text { manage high-risk and } \\
\text { suspect cases }\end{array}$ & $\begin{array}{l}\text { Tightening of } \\
\text { accompanying visitor } \\
\text { policies and } \\
\text { modification of } \\
\text { protocols based on } \\
\text { evolving situation }\end{array}$ & & $\begin{array}{l}\text { Easing of visitor } \\
\text { limitations }\end{array}$ & $\begin{array}{l}\text { Adequate equipment } \\
\text { for thermal screening } \\
\text { and registration stations } \\
\\
\text { Drawer plans for triage } \\
\text { and escalation protocol }\end{array}$ \\
\hline & $\begin{array}{l}\text { Mask-fitting exercises and PPE donning } \\
\text { and doffing retraining for frontline staff }\end{array}$ & $\begin{array}{l}\text { Mask-fitting exercises } \\
\text { and PPE donning and } \\
\text { doffing retraining for } \\
\text { healthcare staff }\end{array}$ & & & $\begin{array}{l}\text { Refresher training and } \\
\text { competency } \\
\text { assessments }\end{array}$ & $\begin{array}{l}\text { Regular refresher } \\
\text { training and } \\
\text { competency } \\
\text { assessments }\end{array}$ \\
\hline Psychological defense & $\begin{array}{l}\text { Mental health initiatives to ensure and } \\
\text { sustain wellbeing of staff }\end{array}$ & $\begin{array}{l}\text { Ongoing evaluation of } \\
\text { staff well-being and } \\
\text { continuation of } \\
\text { initiatives }\end{array}$ & & & $\begin{array}{l}\text { Identification of post- } \\
\text { traumatic stress disorder } \\
\text { features and } \\
\text { establishing avenues of } \\
\text { support }\end{array}$ & $\begin{array}{l}\text { Established mental } \\
\text { health services and } \\
\text { resources for healthcare } \\
\text { staff }\end{array}$ \\
\hline
\end{tabular}


overcrowding issues in foreign worker dormitories. The virus spread rapidly amongst individuals housed in tight living spaces $^{3}$ and the healthcare system has had to adapt to these changes vis-à-vis public health measures enacted to curtail the rate of transmission. Through this experience, our Ophthalmology department has learnt both valuable and painful lessons which have been useful during the pandemic, yet have also exposed the vulnerabilities of our 'peacetime' setup. We hope to share our experience and the effect of these interventions at various critical time points (Table 1) with the global medical community, and hope that our international colleagues will be able to draw from our insights, enacting changes to benefit their daily practice.

To understand how this situation has impacted upon our ability to function, it is necessary to understand how the Singaporean public healthcare system is organized. The National University Health System is one of three healthcare clusters within Singapore. ${ }^{4}$ Each cluster comprises an integrated network of medical institutions (hospitals and specialist care centers) which afford tertiary level care, as well as community hospitals (providing step-down care) and polyclinics which provide primary care services. Ophthalmic services within each cluster are coordinated through a parent site, with resources disseminated downstream into satellite sites.

In response to the 2003 Severe Acute Respiratory Syndrome (SARS) pandemic, the Singaporean government designed'Disease Outbreak Response System Condition (DORSCON)' as a color-coded framework to detail the prevailing disease situation. ${ }^{5}$ Singapore was one of the first countries to identify imported cases of COVID19 , and the DORSCON alert was raised to 'Orange' on 7 February 2020 in response to verified community transmission of COVID-19. Despite this, further community spread necessitated implementation of 'circuit breaker' measures which were first announced on 3 April 2020, with a further slew of measures announced on 21 April $2020 .{ }^{6}$ Singapore has since adopted a three-phased approach to resuming social, economic, and entertainment activities, which commenced from 2 June 2020.

\section{Operations}

Upon escalation to DORSCON Orange, a disease outbreak taskforce was assembled and embedded within our operations team. This comprised of the cluster head, clinical directors, chief residents, clinic managers and heads of the nursing and allied health team.

In non-pandemic times, the department's structure was geared towards free movement of personnel to cross-cover services across the cluster. This arose from the tenets of developing a lean and economically viable service, devolving care from tertiary care centers, and upskilling of primary eye care services. Many of these plans were still in their infancy when COVID-19 hit. 


\section{Withdrawing of personnel from community-based satellite sites}

Governmental directives during the initial phases of DORSCON Orange limited healthcare personnel to practicing in one institution. A decision was made to shut down satellite community ophthalmic sites and withdraw manpower to our parent site, as they were not networked and equipped with sufficient ophthalmic investigation equipment to function independently. Furthermore, satellite sites were manned by both an optometrist and ophthalmologist, with both required back at the parent site. Ideally, devolved care from tertiary centers to community-based, independent primary eye care practitioners within a distributed care network mitigates risks of developing transmission clusters within a central site. Subsequent identification of positive clusters can be dealt with by closing affected nodes sequentially. These sites should function independently and remain supported by specialist input remotely using a distributed imaging network and central repository system.

Unfortunately, Singapore is yet to possess an established primary eye care network. Furthermore, with internet separation hailed as a nationwide panacea to cyber-attacks, the health-based IT network has lost its ability to seamlessly integrate with other networks. ${ }^{7}$ The inability to devolve care to disseminate and distribute work meant that a significant onus of postponing appointments and subsequent follow-ups fell on personnel within the parent site. The process was hampered by bureaucracy and outdated computer systems that required many man-hours to generate, sort, and manage data. Automation of these processes and integrating appointment-based systems with internet and mobile-based platforms, where patients can verify and modify existing appointments, would have been valuable in this regard.

With relaxing of restrictions surrounding movement of personnel between institutions, these community sites have been reopened. Plans are underway to implement a cluster-wide electronic medical records system to provide patients with seamless care between sites, and to facilitate teleconsultations between community-based practices and our subspecialty services, which are predominantly based at our tertiary centers.

\section{Manpower}

\section{Team segregation}

At our parent site, staff were segregated into two teams with equal representation of subspecialties in each team. At any time, one team shouldered a heavier outpatient clinic load while the other handled inpatient clinical duties and a relatively smaller number of outpatients, along with administrative tasks of screening prospective patients' medical records with the intent to reschedule 
non-urgent clinic appointments. Teams were rotated weekly. The clinic was further partitioned into two separate physical spaces.

The concept of team segregation was put to the test when staff on outpatient clinic duties were inadvertently exposed to a patient (who had not displayed overt symptoms of a respiratory tract infection then) who subsequently tested positive for COVID-19. Teams were immediately swapped and staff in direct contact with the patient were promptly isolated. While this demonstrates the utility of team segregation, the obvious downside to such a plan is that the department's continuity is limited to a single contact rate, where another exposure event could have shut the department down. Further driving this issue, as a problem that is almost peculiar to ophthalmology, is the perceived pressure towards subspecialization. This pressure is influenced by increasing medicolegal concerns and reliance on subspecialty input, which is further sustained by the presence of a geographically small and densely populated country, where sub-specialists are relatively easily accessed and consults easily sourced. The benefit to such an approach is that patients obtain a focused, targeted approach to their problems. Pitfalls, however, include the need for a large team of specialists to provide comprehensive ophthalmic care.

Desegregation of teams within the institution has since been initiated at the directive of the hospital's operations team. This has provided our department with the opportunity to relook, revamp, and optimize our workflow and clinic services.

\section{Cross-cluster and international collaboration}

Interconnectivity between ophthalmology departments of each cluster permitted cross-cover of patients requiring emergent review. Staff were tested positive in another ophthalmology cluster and outpatient visits to their institution were temporarily ceased as a precautionary measure. Plans were made for cases presenting to their cluster requiring acute intervention to be diverted to our hospital to assist with ongoing management of these patients.

Our department also cares for a significant proportion of international patients within the region. Border closures and entry restrictions have limited the travel of patients into Singapore for their consultations. Care of many of these patients has been provided with the expertise of local ophthalmologists, in consultation with our specialty teams. This experience reinforced the importance of the longstanding spirit of collaboration between institutions locally and globally.

\section{Visiting consultants}

Our department has visiting ophthalmologists, who took time off from their private practice to care for patients within the public sector. When cross-institutional movement was banned, many visiting ophthalmologists were barred 
from running clinics at public health institutions. This has since been relaxed, with governmental bodies recognizing the protracted duration of this pandemic. Although our present setup has limited the impact of this decision, other practices with a larger proportion of visiting specialists may have been impacted more significantly. This is translatable to situations in other healthcare systems, where visiting specialists may make up a significant proportion of the workforce within the public health system. It may therefore be timely to revisit remuneration of these specialists through the public health system; for instance, as a pandemic-related incentive, which may serve as an effective strategy to make public health institutions a more attractive proposition, should there be future occurrences.

\section{Supporting critical services}

Further assistance was sought from the Ophthalmology team to support national and cluster-based efforts to ramp up support to critical care and COVID-19 isolation-related services. Junior medical staff were deployed to support critical services through secondment to the Emergency Department to assist with the influx of patients, whilst staff were earmarked to support efforts at the National Centre for Infectious Diseases. Healthcare workers were also sent upstream to establish medical outposts and swab-testing at migrant worker dormitories, to minimize movement of patients to the acute hospitals This series of events exposed our relative reliance on junior manpower, which is inevitable especially within the public health system, where multiple consultation rooms run by junior ophthalmologists are supervised by a consultant.

This has however provided the impetus to restructure clinics, such that clinics are consultant-run rather than consultant-led, with patient numbers determined by what each consultant can see. This has been possible due to the relatively healthy manpower staffing of ophthalmologists within the public health system in Singapore.

\section{Caring for our overseas staff}

Singapore has a small labor base and is dependent on a large proportion of migrant workers, with an estimated 300,000 Malaysians commuting daily to Singapore between the land border of both countries. ${ }^{8}$ Announcement of the Malaysian Movement Control Order; a cordon sanitaire, on 18 March, limited cross-border movement of individuals. This predominantly affected our nursing and allied health staff, and national plans were made to match stranded workers with temporary accommodation. Staff with families in Malaysia were permitted to take voluntary no-pay leave to spend time with their family during this period. 


\section{Protection of staff}

\section{Personal protective equipment}

One of the key considerations is ensuring that staff were adequately protected, particularly given that ophthalmology has been reported as a high-risk specialty for the development of COVID-19. ${ }^{9}$ This has been attributed to the proximity with patients required as part of the examination process, along numerous high-touch surfaces involving our investigation and examination equipment. ${ }^{10}$ SARS-CoV-2 has also been detected on the ocular surface and its secretions. ${ }^{11}$

Logistical aspects included ensuring that personal protective equipment (PPE) supplies were available, and adequately protecting against exposure based on our understanding of disease transmission. This has been challenging given that information is constantly evolving; predominantly surrounding the transmission route of droplets versus aerosolization. This has been made complicated by differing recommendations by government agencies worldwide and practices by ophthalmology colleagues globally. ${ }^{12}$ Although discussions were had regarding the use of $\mathrm{N} 95$ respirators on a regular basis, use of surgical masks for all healthcare workers facing patients was decided upon given the limited duration of exposure to patients by staff, and considerations regarding rationing of PPE supplies. Given considerations regarding aerosolization, air puff tonometry was stopped and aerosol-generating procedures were kept to a minimum. ${ }^{13}$ Learning from our Hong Kong colleagues, we fashioned larger breath shields out of X-ray films, which have been gradually replaced by purpose-made polycarbonate shields from vendors. ${ }^{14}$

Meticulous and diligent wiping down of surfaces and practice of hand hygiene is also crucial in decreasing the risk of transmission amongst patients and staff. ${ }^{15}$ However, this may not always be possible. For instance, concerns were raised surrounding cleaning of the Humphrey ${ }^{\circledR}$ Field Analyzer (Carl Zeiss Meditec AG, Jena, Germany) machine testing bowls. Upon clarification with the vendor, it was advised that wiping these surfaces down may damage equipment and void the validity of tests performed. It was further deemed that universal mask wearing would decrease risks associated with this mode of transmission.

These experiences have taught us the importance of knowledge-sharing and staying abreast with the latest advances to ensure that staff are protected in accordance with the latest recommendations.

\section{Mitigating exposure risks}

At the clinic level, prospective patient lists are thoroughly vetted and appointments rescheduled to reduce clinic numbers. Patients are contacted prior to their appointments to enquire about their travel, contact history, and the presence of any acute respiratory symptoms via a verbal screening questionnaire. Patients providing positive responses are advised to reschedule their appointments and 
seek medical attention when necessary. Any concerns regarding a deterioration in their condition or new ophthalmic complaints are escalated to the responsible ophthalmologist.

Thermal screening and visitor registration stations have been set up at the entrance of our specialist outpatient center. Besides universal masking as a condition of entry, patients and their caregivers complete a health declaration form and are triaged per their responses. Those with acute respiratory symptoms, or a positive travel or contact history are tagged with a sticky label and escorted by a security officer to isolation rooms within our clinic. A member of the Ophthalmology team subsequently evaluates both the patient's ophthalmic condition and respiratory symptoms remotely via a telephone call, and either provides an initial management plan or dons full PPE to evaluate the patient. Patients are either discharged with medical advice to self-monitor and present to the emergency department in the event of any further deterioration, or the case escalated to the COVID-19 infectious diseases team onsite for further management advice.

Plans for virtual clinics were expedited for a range of conditions including glaucoma suspect screening, diabetic retinopathy, and hydroxychloroquine screening. Although our present setup necessitates patients attending for investigations, having the ophthalmologist review results remotely reduces the number of individuals the patient comes in contact with and potentially enables some ophthalmologists to work from home. Such virtual clinic pathways have been well described in the literature. ${ }^{16,17}$ Further initiatives include integration of telehealth pathways in our daily practice, such as phone review of symptoms for patients who had undergone uncomplicated cataract surgery at the first postoperative week. ${ }^{18}$ These initiatives have been found to be safe and effective and have been integrated into our existing suite of clinical services.

Non-urgent surgery was also been postponed, resulting in a reduction of approximately $80 \%$ of cases. Only urgent ophthalmic surgeries were allowed to proceed, contingent upon approval from the department head and chairperson of the operating theatre committee. These restrictions have since been relaxed. In situations where general anesthesia is necessary, only essential staff are allowed into the operating theatre during the intubation process. We debated the use of $\mathrm{N} 95$ masks for ophthalmic surgery, as the practice varies internationally. Based on the current level of evidence, this was only used with aerosol-generating procedures, such as pars plana vitrectomies. ${ }^{19}$

\section{Protecting vulnerable staff}

Vulnerable staff, such as pregnant personnel, were reassigned to assist with administrative tasks and virtual clinics. When possible, staff were allowed to work from home to complete these tasks. 


\section{Mental health care}

The impact of this pandemic upon an individual's mental health is frequently overlooked and understated. Plans to ensure that staff were adequately prepared included hospital-wide initiatives to bolster morale, including mask-fitting exercises for respirators, while refresher courses on donning and doffing of PPE were conducted. This provided staff with the confidence to utilize protective equipment and handle suspected or positive cases.

Understanding the need to ensure the wellbeing of our staff and bolster team morale, initiatives by our medical and nursing staff included planned lunch treats for the entire team and provision of 'care packs'. Many of these initiatives have been performed in collaboration with our food and beverage contacts, along with other industry networks whom have been extremely generous with their contributions.

A flat organizational structure and supportive work-place culture has further built team rapport and solidarity amongst staff. Our staff have initiated informal 'peer-support' networks to check in on each other, providing platforms to discuss challenging encounters or workplace situations.

\section{Ramping up of services}

The restriction on patient visits during this period has resulted in a marked increase in the waiting time required for ophthalmic appointments. Plans have been put in place to gradually increase clinic numbers whilst adhering to safe-distancing requirements, in line with easing of restrictions nationally. Priority has been provided to patients in our first-visit, glaucoma, and retina services, particularly those with chronic conditions requiring active therapy, or poorly-sighted patients requiring active management.

Patients are also reviewed through virtual clinic and telehealth services that have been established and refined during this period, while stable patients with conditions necessitating review are decanted into satellite sites that will be gradually reopened.

\section{Conclusion}

While the pandemic has upended the way we practice ophthalmology, every cloud has a silver lining. This crisis has provided us with the opportunity to critically analyze and optimize our daily operations, augment our services with telehealth and virtual clinic initiatives, and renew our commitment to establish our primary eye care capabilities. It has also highlighted the need to review a range of national and institutional-based policies across various fronts, to enable healthcare delivery services to take the next step forward in a technologically-enabled society. 


\section{Acknowledgements}

The authors wish to disclose they have no competing interests, conflicts of interest, or sources of funding in regard to this article. No ethical approval was required as the information herein contained concerns policy changes and implementations during the COVID-19 pandemic with no use of clinical or human data.

The authors wish to thank our industry partners who have been so generous in caring for our staff, including: Arly (Ms. Airin), Bayer HealthCare and Regeneron Pharmaceuticals Inc, Krunchy Fritters (Mr. Hafiz), and Sanity Coffee (Ms. Diya Tan).

\section{References}

1. Teo J. Coronavirus: WHO praises Singapore's containment of Covid-19 outbreak. Straits Times. 2020.

2. Bowie N. Cracks show in Singapore's model Covid-19 response. Asia Times. 2020.

3. Han K. Covid forces Singapore to confront conditions for its migrant workers. The Interpreter. 2020.

4. Ministry of Health Singapore. Reorganisation of healthcare system into three integrated clusters to better meet future healthcare needs [Internet]. 2017. Available from: https://www.moh.gov. sg/news-highlights/details/reorganisation-of-healthcare-system-into-three-integrated-clustersto-better-meet-future-healthcare-needs.

5. Ministry of Health Singapore. MOH Pandemic Readiness and Response Plan for Influenza and other Acute Respiratory Diseases2014. Available from: https://www.moh.gov.sg/docs/ librariesprovider5/diseases-updates/interim-pandemic-plan-public-ver-_april-2014.pdf.

6. Singapore Government. Circuit Breaker extension and tighter measures: What you need to know. Available from: https://www.gov.sg/article/ circuit-breaker-extension-and-tighter-measures-what-you-need-to-know.

7. Chua A. Current model of Internet separation unsustainable in longer run: $\mathrm{MOH}$ chief data advisor. Today. 2018.

8. Lau J. Malaysians with work permits can continue working in Singapore, says MFA. Straits Times. 2020.Available from: https://www.straitstimes.com/singapore/health/ malaysians-with-work-permits-can-continue-working-in-singapore-says-mfa.

9. Breazzano MP, Shen J, Abdelhakim AH, et al. Resident physician exposure to novel coronavirus (2019-nCoV, SARS-CoV-2) within New York City during exponential phase of COVID-19 pandemic: Report of the New York City Residency Program Directors COVID-19 Research Group. medRxiv. 2020.

10. Kuo IC, O'Brien TP. COVID-19 and ophthalmology: an underappreciated occupational hazard. Infect Control Hosp Epidemiol. 2020:1-9.

11. Xia J, Tong J, Liu M, Shen Y, Guo D. Evaluation of coronavirus in tears and conjunctival secretions of patients with SARS $₫$ CoV\2 infection. J Med Virol. 2020;92(6):589-594.

12. Naveed H, Scantling-Birch $Y$, Lee H, Nanavaty MA. Controversies regarding mask usage in ophthalmic units in the United Kingdom during the COVID-19 pandemic. Eye. 2020:1-3.

13. Britt JM, Clifton BC, Barnebey HS, Mills RP. Microaerosol formation in noncontact air-puff tonometry. Arch Ophthalmol. 1991;109(2):225-228.

14. Wong DH, Mak ST, Yip NK, Li KK. Protective shields for ophthalmic equipment to minimise droplet transmission of COVID-19. Graefes Arch Clin Exp Ophthalmol. 2020:1-3.

15. Qiao C, Zhang H, He M, et al. Symptomatic COVID-19 Infection in Eye Professionals in Wuhan China. Ophthalmology. 2020;127(9):1268-1270. 
16. Zaidi FH, Rennie CA, Drinkwater AK, Sahu D, Akyol E, Lotery AJ. How to set up a Hydroxychloroquine Retinopathy Screening Service. Eye. 2019;33(11):1679-1682.

17. Kotecha A, Bonstein K, Cable R, Cammack J, Clipston J, Foster P. Qualitative investigation of patients' experience of a glaucoma virtual clinic in a specialist ophthalmic hospital in London, UK. BMJ Open. 2015;5(12):e009463.

18. Lim CH, Chai CH, Goenadi CJ, Zhao PS, Tan CW, Lin HA. Feasibility of Post-operative Cataract Surgery Telehealth Consultations in the COVID-19 Era. Unpublished Manuscript. 2020.

19. The Royal College of Ophthalmologists. PPE and staff protection requirements for ophthalmology. In: The Royal College of Ophthalmologists, editor. COVID-19: infection prevention and control (IPC): GOV.UK; 2020. 